\title{
Group G Streptococcus Infective Endocarditis in Association With Colon Cancer
}

\author{
Ashraf Abugroun ${ }^{\mathrm{a}, \mathrm{c}}$, Ramy Zughul ${ }^{\mathrm{a}}$, Mina Tawadrous ${ }^{\mathrm{b}}$, Margiori Rodriguez ${ }^{\mathrm{a}}$
}

\begin{abstract}
Group $\mathrm{G}$ streptococcus has been increasingly reported as a cause of bacteremia and infective endocarditis. The association between various groups of streptococcus with malignancy has been well established. Such association is particularly observed in group D Streptococcus bovis which is commonly reported in association with carcinoma of the colon. We herein report a case of a 72-year-old male who presented with severe sepsis, iron deficiency anemia and newly diagnosed cardiac murmur. Further workup confirmed group $\mathrm{G}$ streptococcus bacteremia, infective endocarditis and newly diagnosed carcinoma of the colon. This case highlights a unique association between invasive form of group $\mathrm{G}$ streptococcus and colon cancer.
\end{abstract}

Keywords: Group G streptococcus; Infective endocarditis; Colon cancer

\section{Introduction}

Infective endocarditis (IE) can be caused by a wide variety of infectious agents. While infective endocarditis caused by the Lancefield group A streptococcus has dominated the medical literature, little was published on the role of other Lancefield groups including group G streptococcus (GGS) on the development of IE. We herein report a case of a 72 years old male who presented with severe sepsis and iron deficiency anemia. Further workup confirmed a diagnosis of IE caused by Lancefield GGS, as well as newly diagnosed colon cancer. This case highlights the aggressive form of GGS manifesting with acute IE in association with newly diagnosed colon cancer.

\section{Case Report}

A 72 years old male with past medical history of chronic

\footnotetext{
Manuscript submitted December 8, 2017, accepted December 20, 2017

aAdvocate Illinois Masonic Medical Center, Chicago, IL, USA

${ }^{b}$ Kansas City University of Medicine, Kansas City, MO, USA

${ }^{\mathrm{c} C}$ Corresponding Author: Ashraf Abugroun, Advocate Illinois Masonic Medical

Center, 836 W Wellington Ave, Chicago, IL 60657, USA.

Email: ashraf.abugroun@advocatehealth.com
}

doi: https://doi.org/10.14740/cr653w healed lower extremity ulcers due to lymphedema was brought to the hospital for evaluation of fever and altered mental status. On admission, vital signs showed temperature $39.1{ }^{\circ} \mathrm{C}$, heart rate 92 beats/min, and respiratory rate 22 breaths/min. Physical examination was remarkable for pallor, systolic murmur along the aortic area. Lungs were clear to auscultation. Abdomen was soft, non-tender, and no organomegally was detected. Examination of the extremities showed multiple healed wounds along both the lower extremities without evidence of infection. His right ankle was swollen and mildly tender to palpation with no erythema or warmth. Labs were remarkable for lactic acid $3.8 \mathrm{~g} / \mathrm{dL}$, white cell counts (WBC) $12.3 \times$ $10^{9} / \mathrm{L}$, hemoglobin $6.5 \mathrm{~g} / \mathrm{dL}$, procalcitonin $54.96 \mathrm{ng} / \mathrm{mL}$, and C-reactive protein (CRP) $19.2 \mathrm{mg} / \mathrm{dL}$. Two sets of blood cultures were obtained. Fluid resuscitation and broad-spectrum antibiotics were initiated. Later his blood culture grew streptococcus G. Given the newly discovered heart murmur, transthoracic echocardiogram (TTE) was obtained and showed a medium sized, $1.0 \mathrm{~cm}$ (length) $\times 1.0 \mathrm{~cm}$ (width), irregular, partially calcified, mobile mass on the left ventricular aspect with appearance consistent with vegetation. Subsequently, transesophageal echocardiogram (TEE) was performed and confirmed aortic valve vegetation (Fig. 1). No other obvious source for bacteremia was identified. Patient underwent right ankle magnetic resonance imaging (MRI) which was negative for osteomyelitis or septic arthritis or abscess. Given the patient's severe microcytic anemia, iron studies were obtained and confirmed severe iron deficiency anemia. He received 4 units of packed red blood cells (PRBCs) during his hospital stay. His low hemoglobin prompted further workup including

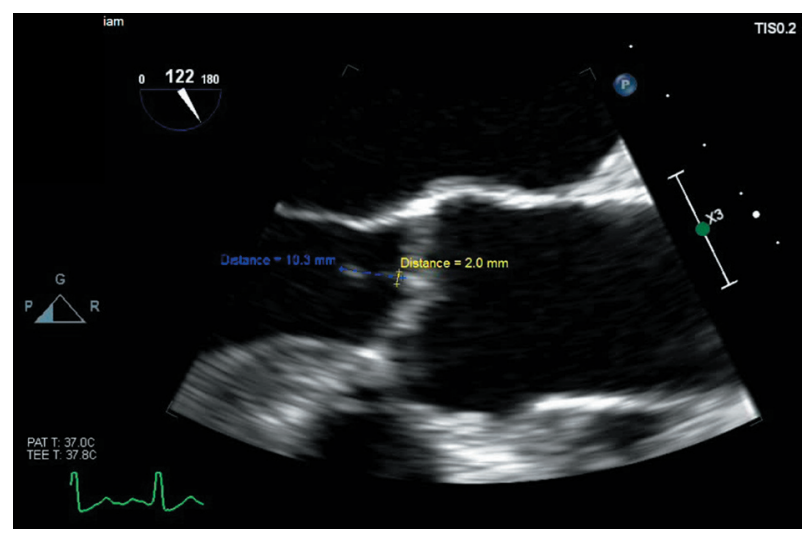

Figure 1. TEE three-chamber view of the mid esophageal region showing $2 \mathrm{~mm}$ vegetation along the aortic valve. 


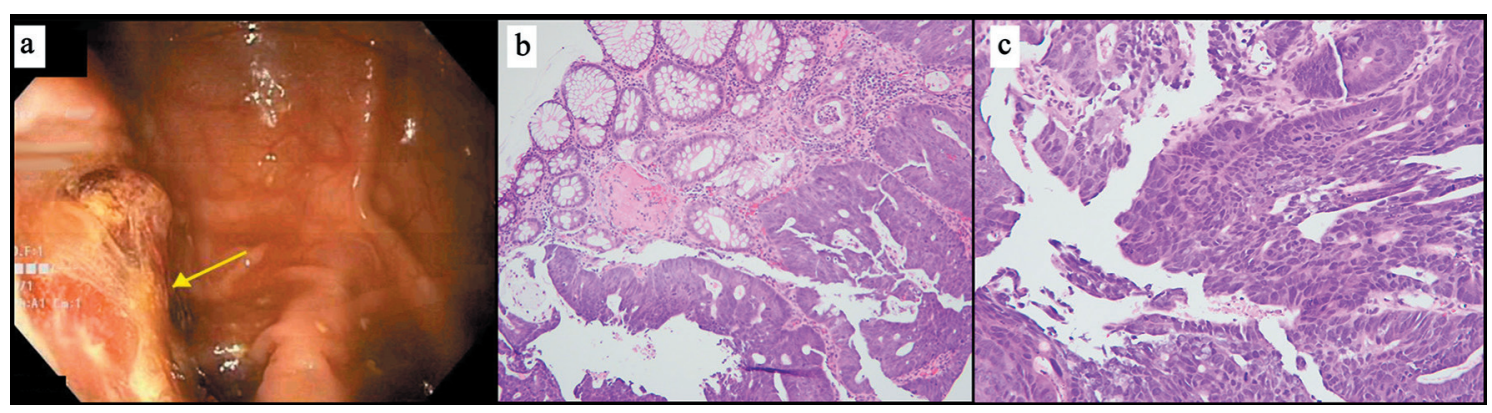

Figure 2. (a) Endoscopic view showing sigmoid colon mass. (b) Microscopic view of biopsy of the sigmoid colon lesion at $\times 100$ magnification showing adenocarcinoma next to benign colonic glands for comparison. (c) Microscopic view of biopsy of sigmoid colon at $\times 200$ magnification showing nuclear and architectural pleomorphism and mitoses.

computed tomography (CT) of the abdomen and pelvis which revealed circumferentially thickened segment of descending colon adjacent to the splenic flexure with localized invasion into the sigmoid colon. Such finding was highly suspicious for primary colonic cancer. CT of the chest showed multiple bilateral pulmonary nodules measuring $1.6 \mathrm{~cm}$ most compatible with metastatic disease. Colonoscopy showed a friable lesion that was partially occluding the lumen and biopsy of the lesion confirmed a diagnosis of adenocarcinoma (Figs. 2, 3 ). Patient was discharged on intravenous (IV) ceftriaxone to complete 6 weeks of antibiotics coverage for IE and follow-up was planned with colorectal surgery.

\section{Discussion}

Lancefield GGS has been recognized as an important cause of streptococcal infection. GGS colonizes the human skin, pharynx and gastrointestinal tract. GGS has been implicated in a wide range of human infections ranging from simple forms of pharyngitis or cellulitis, to more severe forms of infections including bacteremia, infective endocarditis and toxic shocklike syndrome [1-3]. The incidence of GGS related infections is increasing [4]. A recent study reported approximating incidence of the disease compared to group A streptococci (GAS) infections [2]. Such increase in incidence of severe infections related to GGS is partly because of the improvements in labo- ratory techniques allowing increased recognition of the organisms, as well as increase in newly acquired virulence genes that allows the bacteria to produce more severe infections [5].

GGS has morphologic resemblance to GAS, and shares similar virulence factors. The clinical virulence of the bacteria is determined by the presence of M-associated protein which provides profound anti-phagocytic effect $[6,7]$. Common predisposing factors for GGS associated bacteremia include immune suppression, alcoholism, diabetes mellitus, neurological diseases, malignancy and breakdown of the skin [8-10]. Commonly reported portals of entry include cellulitis of the lower extremities, decubitus ulcers and other conditions predisposing to skin breakdown [11]. Though portal of entry of GGS was not determined in our patient, the two possible sources of entry were the intestinal tract given the newly diagnosed ulcerating mass versus the skin, since patient had skin ulcers in lower extremities. However, all skin ulcers were adequately healed and had no evidence of infection making the intestinal route a likely source for bacterial entry.

GGS accounts for approximately $3.5 \%$ of all patients with bacteremia. The incidence of IE secondary to GGS is variable ranging from as low as $1 \%$ of to as high as $25-50 \%$ of cases of IE [12]. The diagnosis of bacterial endocarditis is based on various clinical, laboratory and echocardiographic criteria grouped under DUKE criteria. The modified DUKE criteria are now widespread and utilized clinically for improved diagnosis of IE [13]. This is based on the "major criteria" (typi-
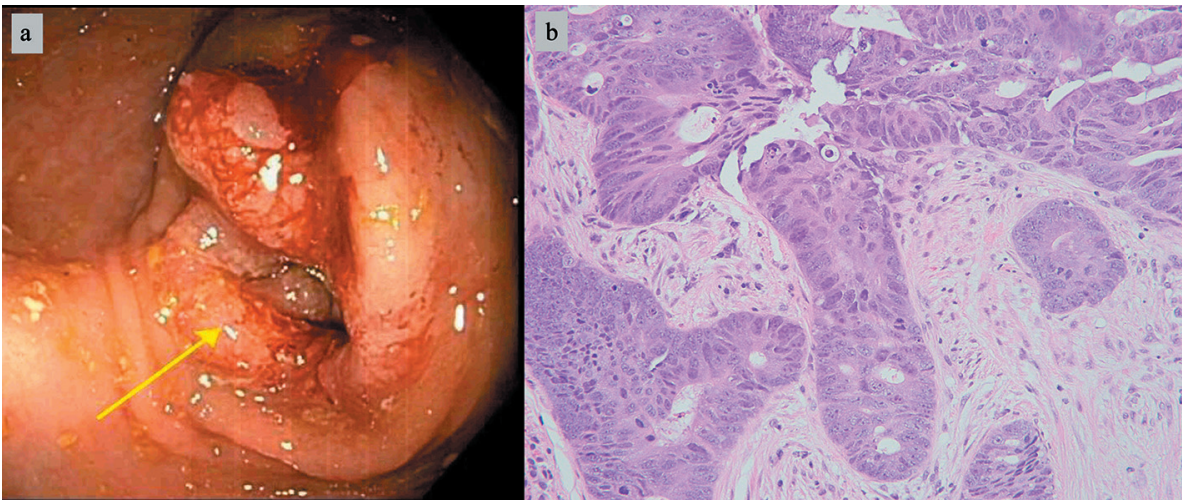

Figure 3. (a) Endoscopic view showing partially obstructing mass in the transverse colon. (b) Biopsy of the transverse colon mass at $\times 200$ magnification showing adenocarcinoma. 
cal blood culture and positive echocardiogram) and six "minor criteria" (predisposition, fever, vascular phenomena, immunologic phenomena, suggestive echocardiogram, and suggestive microbiologic findings).

The association between IE and colon cancer is characteristically seen among patients with IE caused by Streptococcus bovis (viridians group) [14]. IE caused by Streptococcus bovis develops concurrently with colon cancer in up to $18-60 \%$ of cases [15]. In a few cases, colon cancer presents years following the diagnosis of bacteremia, suggestive of a possible carcinogenic role of the organism in the pathogenesis of colon cancer. Conversely, colonic lesions can be the source of entry of the bacteria into the blood stream [16].

The course of GGS endocarditis is often aggressive, compared with the subacute course of endocarditis caused by viridians or group D streptococci [17]. GGS bacteremia has been reported in association with various hematologic malignancies and solid organ tumors [18]. Such association between GGS with cancer remains unexplained with a possible role of bacterial $M$ protein [6]. In our case, the patient was diagnosed with GGS IE occurring concurrently with colonic adenocarcinoma. Only a few cases reported in literature highlighted such rare association [19].

Bacterial endocarditis is characterized by a high concentration of infecting organisms within endocardial vegetation, and accordingly a longer duration of high level of antibiotics is usually required [14]. GGS have high susceptibility to vancomycin, erythromycin, and cephalosporins [20]. Despite in vitro susceptibility of GGS to penicillin $\mathrm{G}$, the in vivo responses have been reported as suboptimal [21]. This is particularly observed in cases of GGS bacteremia associated endocarditis. To enhance the susceptibility of GGS to therapy, some authors recommend addition of gentamicin as adjunctive therapy in severe cases [22]. Accordingly, in such conditions as well as in other life-threatening GGS related infections, a broader coverage and close monitoring are usually required.

\section{Conclusions}

GGS infection has emerged as an important cause of IE that is associated with significant morbidity and mortality. By reporting this case we aim to emphasize on the importance of early recognition, and aggressive treatment. In addition, a positive GGS culture in the setting of IE should at least alert the physician for the possibility of an underlying occult colon cancer that needs to be further investigated. It seems reasonable that investigating malignancy should be a priority in patients with GGS bacteremia.

\section{References}

1. Wong SS, Lin YS, Mathew L, Rajagopal L, Sepkowitz D. Increase in group $\mathrm{G}$ streptococcal infections in a community hospital, New York, USA. Emerg Infect Dis. 2009;15(6):991-993.

2. Broyles LN, Van Beneden C, Beall B, Facklam R, Shewmaker PL, Malpiedi P, Daily P, et al. Population-based study of invasive disease due to beta-hemolytic streptococci of groups other than A and B. Clin Infect Dis. 2009;48(6):706-712.

3. Brandt CM, Spellerberg B. Human infections due to Streptococcus dysgalactiae subspecies equisimilis. Clin Infect Dis. 2009;49(5):766-772.

4. Schwartz IS, Keynan Y, Gilmour MW, Dufault B, LagaceWiens P. Changing trends in beta-hemolytic streptococcal bacteremia in Manitoba, Canada: 2007-2012. Int J Infect Dis. 2014;28:211-213.

5. Ikebe T, Murayama S, Saitoh K, Yamai S, Suzuki R, Isobe J, Tanaka D, et al. Surveillance of severe invasive group$\mathrm{G}$ streptococcal infections and molecular typing of the isolates in Japan. Epidemiol Infect. 2004;132(1):145-149.

6. Bisno AL, Craven DE, McCabe WR. M proteins of group $\mathrm{G}$ streptococci isolated from bacteremic human infections. Infect Immun. 1987;55(3):753-757.

7. Humar D, Datta V, Bast DJ, Beall B, De Azavedo JC, Nizet V. Streptolysin S and necrotising infections produced by group G streptococcus. Lancet. 2002;359(9301):124-129.

8. Cohen-Poradosu R, Jaffe J, Lavi D, Grisariu-Greenzaid S, Nir-Paz R, Valinsky L, Dan-Goor M, et al. Group G streptococcal bacteremia in Jerusalem. Emerg Infect Dis. 2004;10(8):1455-1460.

9. Beebe JL, Koneman EW. Recovery of uncommon bacteria from blood: association with neoplastic disease. Clin Microbiol Rev. 1995;8(3):336-356.

10. Kaplan JD, Musher DM, Hamill RJ. Group G streptococcal bacteremia with presumed endocarditis in a patient with AIDS. West J Med. 1988;149(3):344.

11. Watsky KL, Kollisch N, Densen P. Group G streptococcal bacteremia. The clinical experience at Boston University Medical Center and a critical review of the literature. Arch Intern Med. 1985;145(1):58-61.

12. Venezio FR, Gullberg RM, Westenfelder GO, Phair JP, Cook FV. Group G streptococcal endocarditis and bacteremia. Am J Med. 1986;81(1):29-34.

13. Durack DT, Lukes AS, Bright DK. New criteria for diagnosis of infective endocarditis: utilization of specific echocardiographic findings. Duke Endocarditis Service. Am J Med. 1994;96(3):200-209.

14. Giessel BE, Koenig CJ, Blake RL, Jr. Management of bacterial endocarditis. Am Fam Physician. 2000;61(6):17251732, 1739.

15. Mager DL. Bacteria and cancer: cause, coincidence or cure? A review. J Transl Med. 2006;4:14.

16. Boleij A, Muytjens CM, Bukhari SI, Cayet N, Glaser P, Hermans PW, Swinkels DW, et al. Novel clues on the specific association of Streptococcus gallolyticus subsp gallolyticus with colorectal cancer. J Infect Dis. 2011;203(8):1101-1109.

17. Bouza E, Meyer RD, Busch DF. Group G streptococcal endocarditis. Am J Clin Pathol. 1978;70(1):108-111.

18. Naffaa M, Awad J, Oren I, Braun E, Lavi N. Group G streptococcal endocarditis-associated hemophagocytic syndrome. Int J Infect Dis. 2013;17(12):e1237-1239.

19. Kim NH, Park JP, Jeon SH, Lee YJ, Choi HJ, Jeong KM, Lee JG, et al. Purulent pericarditis caused by group $\mathrm{G}$ streptococcus as an initial presentation of colon cancer. J 
Korean Med Sci. 2002;17(4):571-573.

20. Zaoutis T, Schneider B, Steele Moore L, Klein JD. Antibiotic susceptibilities of group C and group G streptococci isolated from patients with invasive infections: evidence of vancomycin tolerance among group G serotypes. J Clin Microbiol. 1999;37(10):3380-3383.
21. Lam K, Bayer AS. In vitro bactericidal synergy of gentamicin combined with penicillin $G$, vancomycin, or cefotaxime against group $\mathrm{G}$ streptococci. Antimicrob Agents Chemother. 1984;26(2):260-262.

22. Kaye D. Antibiotic treatment of streptococcal endocarditis. Am J Med. 1980;69(5):650-652. 